\title{
Morphological changes of the small-intestinal mucosa of guinea pig and hamster following incubation in vitro and perfusion in vivo with unconjugated bile salts
}

\author{
THOMAS S. LOW-BEER ${ }^{1}$, ROBERTO E. SCHNEIDER, AND \\ WILLIAM O. DOBBINS
}

From the Gastroenterology Research Laboratory, Veterans Administration Hospital, and Department of Medicine, Division of Gastroenterology, Duke University Medical Center, Durham, North Carolina

SUMMARY Incubation in vitro of the intestine of the hamster and guinea pig with $5 \mathrm{mM}$ sodium cholate and with $2 \mathrm{mM}$ sodium deoxycholate and sodium chenodeoxycholate resulted in significant morphological changes compared with control incubations. Generally, no major differences were observed between proximal and distal small intestine or between the species used. Only when guinea pig intestine was incubated with $5 \mathrm{mM}$ cholate was less damage found proximally than distally.

Perfusion in vivo of the intestine of the hamster and guinea pig with Krebs-Ringer phosphate results in separation of the epithelium from the lamina propria without excessive shedding of epithelial cells from villous tips. This change was also seen in specimens taken before perfusion and probably represents unavoidable trauma during handling of the intestine.

In contrast to studies in vitro, regional differences are readily demonstrable with perfusion of bile salts in vivo. Dihydroxy bile salts produce more marked alterations of both proximal and distal small intestine than the trihydroxy bile salt, sodium cholate. Dihydroxy bile salts result in significantly greater alterations in proximal than in distal mucosa.

When $5 \mathrm{mM}$ cholate at $p \mathrm{H} 6.8$ is perfused in the guinea pig, absorption occurs approximately 30 times more rapidly from distal than from proximal segments, while in proximal segments $2 \mathrm{mM}$ chenodeoxycholate is absorbed approximately 15 times more rapidly than $5 \mathrm{mM}$ cholate. A correlation is suggested between the morphological alteration produced in the region of the small intestine by a bile acid and the amount of bile salt passing through the cell. Furthermore, it is proposed that the ileal cells may be damaged to a lesser extent by bile acids normally found in that particular species.

Although unconjugated bile salts may be found in the small intestine under normal physiological conditions, conjugated bile salts predominate (Norman and Sjovall, 1958; Dietschy, Salomon, and Siperstein, 1966; Kim, Spritz, Blum, Terz, and Sherlock, 1966). In contrast, a predominance of unconjugated bile salts has frequently been demonstrated in the small intestine of both humans and animals where an abnormal bacterial flora exists (Kim et al, 1966; Donaldson, 1965; Tabaqchali and Booth, 1966; Rosenberg, Hardi-

Received for publication 8 December 1969.

'Present address: Department of Medicine, Bristol Royal Infirmary, BS2 8HW. son, and Bull, 1967). Unconjugated bile salts have been shown to inhibit several intestinal transport mechanisms (Pope, Parkinson, and Olson, 1966; Forth, Rummel, and Glasner, 1966), to promote epithelial cell injury (Dawson and Isselbacher, 1960; Fry and Staffeldt, 1964), to affect the function of a variety of cell fractions (Palade and Siekevitz, 1956; Whitehouse and Staple, 1959; Weissman, 1964), and to inhibit non-specifically intestinal triglyceride synthesis, cholesterogenesis, and carbon dioxide production (Dietschy, 1967). The experiments reported here were designed first to study morphologically the relative effects of unconjugated bile salts on 
the small intestine following perfusion in vivo and in vitro; second, to determine whether the distal small intestine (the site of active transport of bile salts) has a different sensitivity to these materials than does the proximal small intestine; and third, to investigate whether morphological changes are more related to the quantity of bile salt being absorbed than to the concentration within the lumen, especially in the proximal small intestine.

\section{Material}

The species used in these experiments were golden hamsters (90 to $170 \mathrm{~g}$ ) and adult albino guinea pigs of the Hartley strain (200 to $650 \mathrm{~g}$ ). Both species have gallbladders but each has a different bile salt excretion pattern. Conjugated chenodeoxycholate is the primary bile salt of the strain of guinea pigs used (Haslewood, 1964); in the hamster conjugates of cholate predominate, with smaller amounts of chenodeoxycholate and deoxycholate (Prange, Christensen, and Dam, 1962), data further confirmed in our laboratory. The animals were fed Purina hamster laboratory chow and Purina guinea pig chow before study. The unconjugated bile salts used in these experiments were obtained either from Maybridge Chemical Co, Cornwall, UK, or from Dr Leon Lack, Department of Physiology and Pharmacology, Duke University Medical Center, USA, and $24-{ }^{14} \mathrm{C}$-cholic acid and $24-{ }^{14} \mathrm{C}$-chenodeoxycholic acid from Mallinckrodt Nuclear, Orlando, Florida, USA. The purity of bile salts used in these experiments was ascertained by thin-layer chromatography and assay of the melting point. When necessary, purification and recrystallization were performed as described by Norman (1955). A final purity of over $98 \%$ was achieved.

\section{Methods}

\section{INCUBATION in vitro}

The unconjugated bile salts were prepared by dissolving the purified material in distilled water at a temperature of $45^{\circ}$ to $50^{\circ} \mathrm{C}$. Neutralization was accomplished with $1 \mathrm{~N} \mathrm{NaOH}$. $\mathrm{NaCl}, \mathrm{KCl}$, and $\mathrm{Na}_{2} \mathrm{HPO}_{4}$ were added as required to form a calcium-and magnesium-free Krebs-Ringer phosphate solution. The solution was titrated to pH 6.7 with $1 \mathrm{~N} \mathrm{HCl}$. In selected experiments, calcium chloride and magnesium sulphate were added in physiological amounts to the KRP solution which contained no bile salts. All solutions were clear and isotonic.

The animals were fasted for 18 to 24 hours before sacrifice. Guinea pigs were killed by an overdose of ether and the hamsters by cervical dislocation. The abdomen was opened quickly and the small intestine was removed as rapidly as possible, taking care to leave the mesentery intact in order to preserve the serosal surface. The small bowel was placed in cold $\left(2^{\circ}\right.$ to $\left.3^{\circ} \mathrm{C}\right)$ physiological saline and the proximal and distal portions were identified. Between 10 and $12 \mathrm{~cm}$ of each portion was sectioned, rinsed twice with physiological saline, and everted using a glass rod. The everted small bowel was sectioned in segments of 0.5 to $0.7 \mathrm{~cm}$; one segment each from the proximal and distal small bowel was fixed immediately in Bouin's solution as control. Four $\mathrm{ml}$ aliquots of unconjugated bile salt (sodium cholate, sodium deoxycholate, and sodium chenodeoxycholate $1 \cdot 0,2 \cdot 5$, and $5.0 \mathrm{mM}$ respectively in Krebs-Ringer solution) were pipetted into $25 \mathrm{ml}$ Erlenmeyer flasks before the sacrifice of the animal. An additional flask contained only Krebs-Ringer solution and was used as an incubation control. A segment of everted small bowel was then placed in each flask and incubated in a water bath shaker at $37^{\circ} \mathrm{C}$ under $95 \%$ oxygen for one hour. The shaker water bath had a speed of 20 to 22 movements per minute. Ten segments of everted proximal and distal small bowel were incubated in each experiment. There was no change in the $p \mathrm{H}$ of the incubating solutions during these experiments.

\section{PERFUSION in vivo}

The preparation for these experiments has been detailed previously (Heaton and Lack, 1968; Low-Beer, Tyor, and Lack, 1969). A Sigma motor pump calibrated to give the same rate of flow of $4.5 \mathrm{ml}$ per minute for two channels was used, and the infusate maintained at a temperature of $37^{\circ} \mathrm{C}$. Unconjugated bile salts were dissolved in physiological saline and buffered with $0.01 \mathrm{~N}$ sodium phosphate adjusted to $\mathrm{pH} \quad 6.8$. The final solution was isotonic. The concentrations and flow rates were such that the effluent concentration of bile salt was not appreciably altered, hence all parts of the perfused intestine were exposed to the same concentration (Heaton and Lack, 1968). The $p \mathrm{H}$ was also unchanged at the end of the perfusion, and the total volume of effluent recovered from each intestinal segment during the one-hour perfusion was similar in all experiments. When absorption of bile salt was measured, approximately $5 \mu \mathrm{c}$ of the appro-

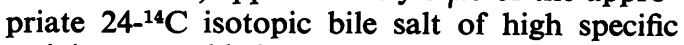
activity was added to each litre of perfusate for subsequent estimation in the bile. The animals were anaesthetized, the abdomen was opened, and proximal and distal small bowel were identified. Isolated loops were prepared in both proximal and distal intestine; these measured 15 to $38 \mathrm{~cm}$ in the guinea pig and 9 to $10 \mathrm{~cm}$ in the hamster. In the hamster the inlet catheter of the proximal loop was inserted $3 \mathrm{~cm}$ below the entry of the bile duct into the duodenum, and in the guinea pig the inlet catheter of the proximal loop was 
placed at the ligament of Treitz. A segment of the small bowel proximal to the inlet catheter of the proximal loop was resected and fixed in Bouin's solution as a control. An outlet catheter with a lumen diameter double that of the inlet catheter was placed appropriately. A similar isolated loop was constructed in the distal bowel, placing the outlet catheter as near the ileocaecal valve as possible. A control segment for histology was taken between the ileocæcal valve and the outlet catheter. The bowel was then replaced in the abdominal cavity.

Bile salt absorption was measured in 10 guinea pigs. In these experiments bile was collected from the cannulated common bile duct, and only one loop of intestine was perfused in each animal. The length of proximal intestine perfused averaged $26 \mathrm{~cm}$ and of distal intestine $32 \mathrm{~cm}$. The methods of analysis have been described in detail elsewhere (Heaton and Lack, 1968; Low-Beer et al, 1969). In outline, the methods used were as follows: bile was collected in calibrated centrifuge tubes for six 10-minute periods and the volumes were noted. The bile was then made up to a standard volume with water and aliquots were measured for radioactivity in a liquid scintillation counter. The bile was sufficiently dilute to avoid complications due to quenching. The amount of bile salt absorbed was calculated by relating the radioactivity recovered in the bile to the specific activity of the perfusion fluid.

At the end of the one-hour perfusion period, the abdominal cavity was opened, the loops were carefully resected, placed in cold $\left(2^{\circ}\right.$ to $\left.3^{\circ} \mathrm{C}\right)$ physiological saline, and measured. Intestinal segments were then taken from a site $2 \mathrm{~cm}$ from the inlet catheter and also from the middle of each loop and fixed immediately in Bouin's solution.

The segments fixed in Bouin's solution were dehydrated and embedded in paraffin, serially sectioned at $5 \mu$ thickness, and stained with haematoxylin and eosin and with periodic acid Schiff and haematoxylin. Two hundred and fifty or more sections were prepared from each segment, and examined by light microscopy.

\section{Results}

Five hundred and thirty-eight biopsies were studied by two of the present authors without knowledge of the species examined, the bile salt used, or the particular procedure. It was agreed that morphological changes observed should be classified on the following scale: 0 should indicate no change, \pm a nonspecific change (see Fig. 1a and b). Abnormal changes were graded as follows: + for a mild shedding of the cells (Fig. $2 a$ and $b),++$ for a moderate shedding of the cells, and +++ for a severe shedding of the cells (Fig. 3a and b). Agreement between the observers

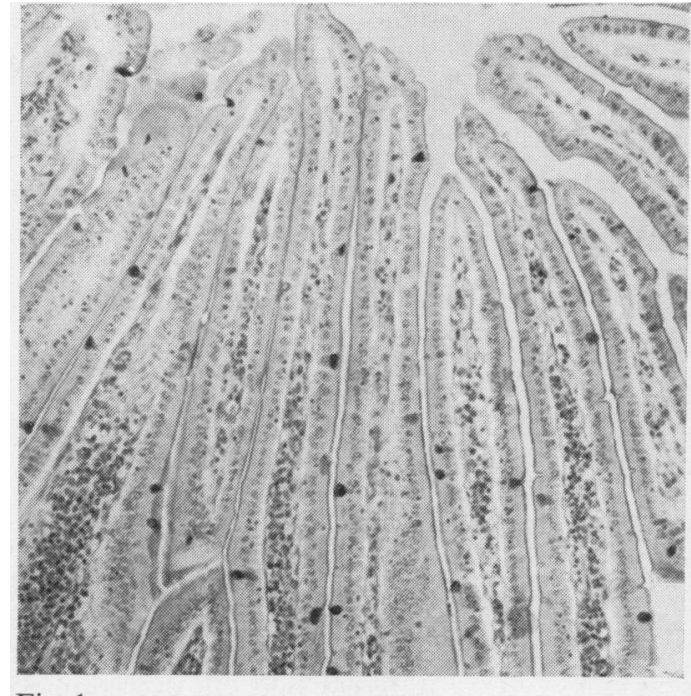

Fig. 1a.

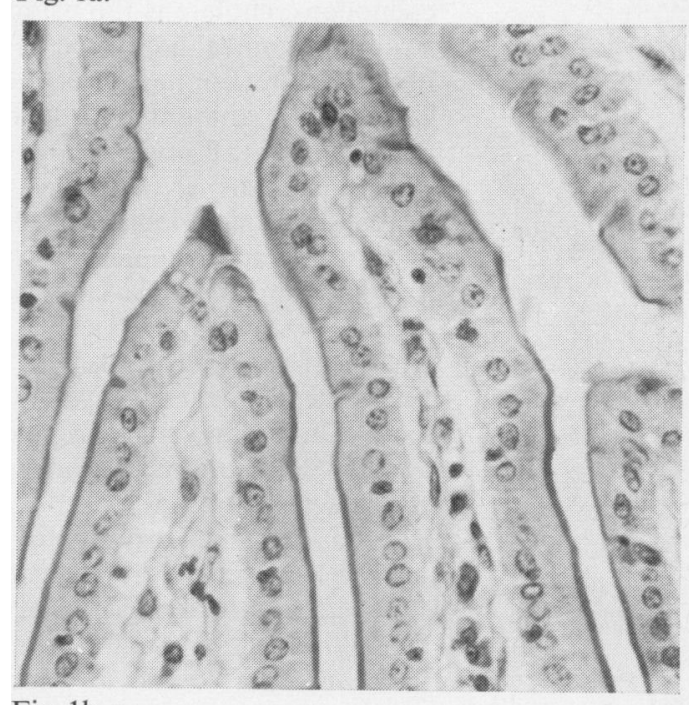

Fig. 1b.

Figs. 1, 2 and 3 Light micrographs of Bouin-fixed, paraffin-embedded sections of proximal intestinal mucosa in the hamster following perfusions in vivo. The histological changes after incubation in vitro and perfusion in vivo were qualitatively identical. Sections were stained with the $P A S$ reaction and haematoxylin. The low magnifications are $\times 190$ and the high magnifications $\times 750$.

Fig. 1a and b Control segment illustrating nonspecific change $( \pm)$ of separation of epithelium from the lamina propria.

working independently was obtained in $98 \%$ of the biopsies. In the remaining $2 \%$, the disagreement was marginal, ie, whether + or \pm , or + or ++ , and was resolved by discussion. A few experiments were repeated in which control biopsies showed extensive lymphocytic infiltration of the mucosa. These changes were presumably due to illness of the animal. 


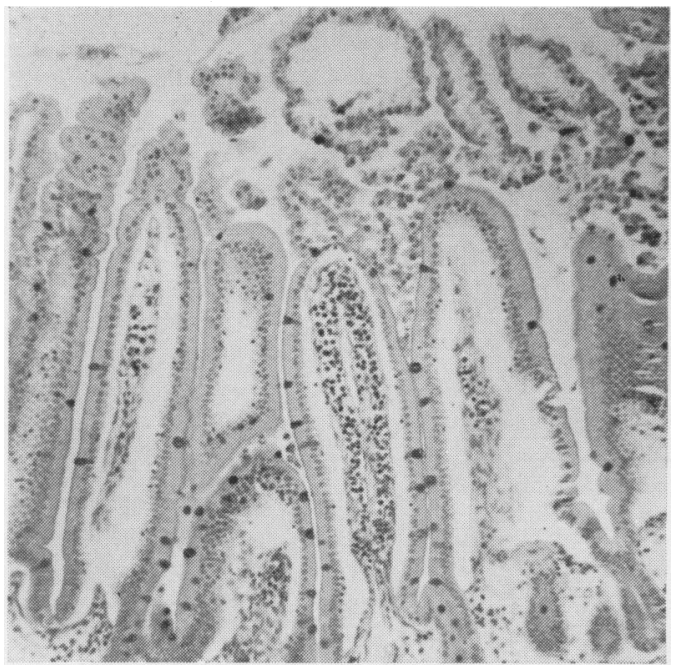

Fig. 2a.

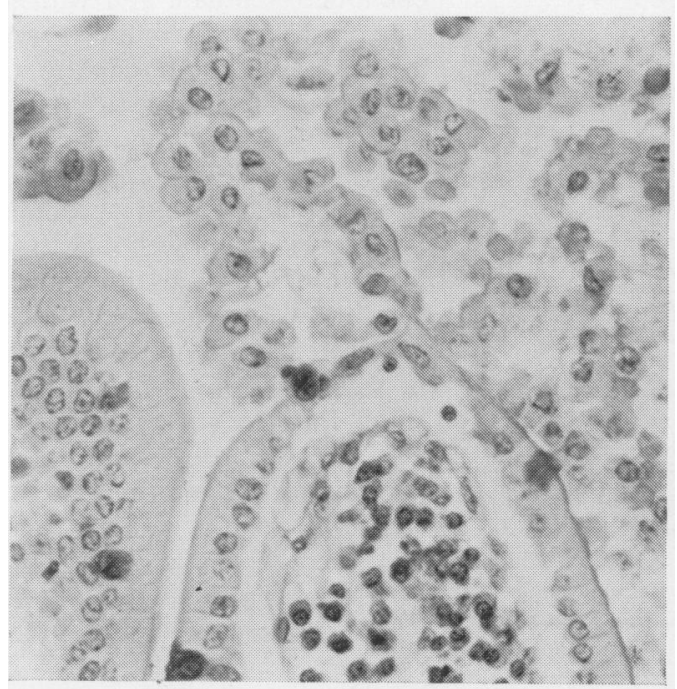

Fig. $2 b$.

Fig. 2a and b Segment illustrating mild abnormality $(+)$ of separation of epithelium from lamina propria with slight shedding of epithelial cells from villous tips.

The lesions noted were located exclusively in the upper third of the villi. When present, they were similar following incubation in vitro and perfusion in vivo. In both situations, there was excessive shedding of epithelial cells from villous tips (Figs. 1-3). The ++ and +++ change could be detected grossly with the dissecting microscope. The desquamated cells appeared similar in control experiments and in those where bile salt was used. The only difference was in the degree of desquamation. No changes were observed in the lamina propria, muscularis mucosa, or submucosa. The desquamated cells were rounded in shape and there was increased eosinophilia of the cytoplasm. The nuclei were

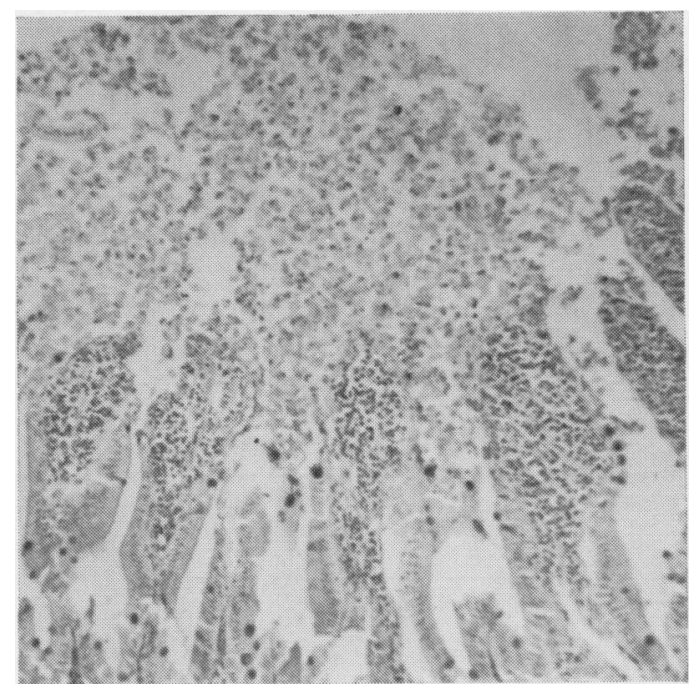

Fig. 3a.

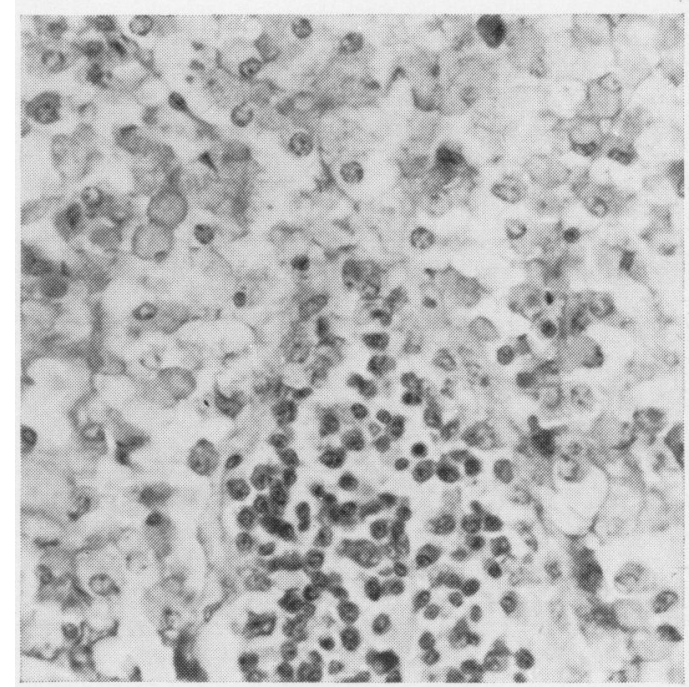

Fig. 3b.

Fig. 3a and b Segment illustrating severe abnormality $(+++)$ with marked shedding of epithelial cells from villous tips in addition to separation of epithelium from lamina propria.

pyknotic and showed prominent clumping of nuclear chromatin about their periphery, changes characteristic of cell injury. Other cells appeared swollen and contained disrupted cytoplasmic membranes, and these were present less often in control experiments.

INCUBATION in vitro

Seven incubations were performed using the small intestine of four hamsters and three guinea pigs. A summary of the changes observed is shown in Tables I and II. Nonspecific changes $( \pm)$ and minimal damage $(+)$ were observed in the specimens incubated only with Krebs-Ringer 
solution. Control un-incubated specimens were normal or showed nonspecific changes only. Morphological changes in villous structure were similar in proximal and distal small bowel in the hamster, and in the guinea pig studied with sodium deoxycholate and chenodeoxycholate. Sodium cholate in guinea pigs produced changes not significantly different from the incubated controls, except when distal small intestine was incubated at a concentration of $5 \mathrm{mM}$. In the latter experiment, moderate damage was produced which

\begin{tabular}{|c|c|c|c|c|c|}
\hline \multirow[t]{2}{*}{ Bile Salt } & \multirow[t]{2}{*}{ Concentration (mM) } & \multicolumn{2}{|c|}{ Three Guinea Pigs } & \multicolumn{2}{|c|}{ Four Hamsters } \\
\hline & & Proximal & Distal & Proximal & Distal \\
\hline Na cholate & $\begin{array}{l}1 \\
2 \cdot 5 \\
5 \cdot 0\end{array}$ & $\begin{array}{l} \pm \\
+ \\
+\end{array}$ & $\begin{array}{l}+ \\
+ \\
++\end{array}$ & $\begin{array}{l}0 \text { to } \pm \\
+ \\
++\end{array}$ & $\begin{array}{l} \pm \\
+ \\
++\end{array}$ \\
\hline Na deoxycholate & $\begin{array}{l}1 \cdot 0 \\
2 \cdot 5 \\
5 \cdot 0\end{array}$ & $\begin{array}{l}+ \\
+t \\
++t\end{array}$ & $\begin{array}{l}+ \\
++ \\
+++\end{array}$ & $\begin{array}{l}+ \\
+++ \\
+++\end{array}$ & $\begin{array}{l}+ \\
+ \\
++ \\
++t\end{array}$ \\
\hline Na chenodeoxycholate & $\begin{array}{l}1 \cdot 0 \\
2 \cdot 5 \\
5 \cdot 0\end{array}$ & $\begin{array}{l} \pm \text { to }+ \\
++ \\
+++\end{array}$ & $\begin{array}{l} \pm \\
t+ \\
t+\end{array}$ & $\begin{array}{l}+ \\
++ \\
+++\end{array}$ & $\begin{array}{l}+ \\
++ \\
+++\end{array}$ \\
\hline
\end{tabular}

Table I Histological damage after incubation in vitro using unconjugated bile salts

\begin{tabular}{llllll}
\hline Krebs-Ringer Phosphate Solution & \multicolumn{2}{l}{ Five Guinea Pigs } & & \multicolumn{2}{l}{ Five Hamsters } \\
\cline { 2 - 3 } \cline { 5 - 6 } & Proximal & Distal & & Proximal & Distal \\
\hline Alone & \pm to + & \pm & & + & \pm \\
Ca added & \pm to + & \pm to + & \pm to + & \pm to + \\
Mg added & \pm to + & \pm to + & + & + \\
Mg and Ca added & + & + & + & + \\
\hline
\end{tabular}

Table II Histological damage after incubation in vitro using Krebs-Ringer solution as control

\begin{tabular}{|c|c|c|c|c|c|c|c|}
\hline \multirow[t]{2}{*}{ Bile Salt } & \multirow{2}{*}{$\begin{array}{l}\text { Concen- } \\
\text { tration } \\
(m M)\end{array}$} & \multicolumn{3}{|c|}{ Guinea Pig } & \multicolumn{3}{|l|}{ Hamster } \\
\hline & & Number & Proximal & Distal & Number & Proximal & Distal \\
\hline $\begin{array}{l}\text { Control perfusion } \\
\mathrm{Na} \text { cholate } \\
\mathrm{Na} \text { deoxycholate } \\
\mathrm{Na} \text { chenodeoxy- }\end{array}$ & $\begin{array}{l}5 \\
1\end{array}$ & $\begin{array}{l}2 \\
3 \\
2\end{array}$ & $\begin{array}{l}0 \text { to }+ \\
0 \text { to } \pm \\
++\end{array}$ & $\begin{array}{l}0 \text { to } \pm \\
++ \\
0\end{array}$ & $\begin{array}{l}2 \\
2 \\
2\end{array}$ & $\begin{array}{l}0 \text { to } \pm \\
0 \\
++\end{array}$ & $\begin{array}{l}0 \text { to } \pm \\
+ \\
+\end{array}$ \\
\hline $\begin{array}{l}\text { cholate } \\
\mathrm{Na} \text { deoxycholate } \\
\text { Na chenodeoxy- }\end{array}$ & $\begin{array}{l}1 \\
2\end{array}$ & $\begin{array}{l}2 \\
2\end{array}$ & $\stackrel{+}{++}$ & $\begin{array}{l}0 \text { to } \pm \\
+++\end{array}$ & $\begin{array}{l}2 \\
2\end{array}$ & $\begin{array}{l}++ \\
+++\end{array}$ & $\begin{array}{l}+ \\
+\end{array}$ \\
\hline cholate & 2 & 3 & ++ & 0 to + & 2 & ++ & ++ \\
\hline
\end{tabular}

Table III Histological damage after perfusion in vivo using unconjugated bile salts

\begin{tabular}{|c|c|c|c|c|c|c|c|}
\hline \multirow[t]{3}{*}{ Bile Salt } & \multirow{3}{*}{$\begin{array}{l}\text { Concen- } \\
\text { tration } \\
(m M)\end{array}$} & \multicolumn{6}{|c|}{$\begin{array}{l}\text { Recovery from Bile Fistula during 60-Min Perfusion } \\
(\mu M)\end{array}$} \\
\hline & & \multicolumn{3}{|c|}{ Proximal Small Intestine } & \multicolumn{3}{|c|}{ Distal Small Intestine } \\
\hline & & Mean & Range & Exps. & Mean & Range & Exps. \\
\hline $\begin{array}{l}\text { Na cholate } \\
\text { Na chenodeoxycholate }\end{array}$ & $\begin{array}{l}5 \\
2\end{array}$ & $\begin{array}{l}1 \cdot 2 \\
18\end{array}$ & $\begin{array}{l}0 \cdot 7-2 \cdot 1 \\
18\end{array}$ & $\begin{array}{l}3 \\
2\end{array}$ & $\begin{array}{l}35 \\
28\end{array}$ & $\begin{array}{l}32-38 \\
25-31\end{array}$ & $\begin{array}{l}3 \\
2\end{array}$ \\
\hline
\end{tabular}

Table IV Absorption of unconjugated bile salts during perfusion in vivo of the small intestine in the guinea pig was greater than in proximal small intestine or in the controls.

Five experiments were performed to evaluate $\Omega$ whether additions of physiological amounts of $\mathrm{Ca}$ and/or $\mathrm{Mg}$ to the Krebs-Ringer solution $\overrightarrow{\vec{F}}$ would prevent the changes observed in control $\stackrel{\rho}{+}$ incubations. The additions of $\mathrm{Ca}$ and/or $\mathrm{Mg}$ did not prevent the changes described (Table II).

\section{PERFUSIONS in vivo}

Control studies were performed in two animals of $\overrightarrow{0}$ each species, using physiological saline only and physiological saline to which was added twice $\vec{\omega}$ the amount of $1 \mathrm{~N} \mathrm{NaOH}$ usually required in the

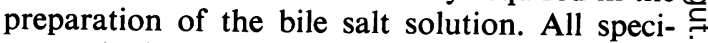
mens obtained showed no change or nonspecific $\overrightarrow{\vec{A}}$ changes. This is in marked contrast to the findings in vitro.

Paired animals from each species were perfused with $1 \mathrm{mM}$ and $2 \mathrm{mM} \mathrm{Na}$ deoxycholate and chenodeoxycholate and with $5 \mathrm{mM} \mathrm{Na}$ cholate. The histological findings are summarized in Table III. Sodium cholate $(5 \mathrm{mM})$ produced significant alterations in the distal small intestine of both species, although there were no associated changes in the proximal segment. Sodium deoxycholate $(1 \mathrm{mM})$ produced changes in the proximal small bowel of both species, and definite alterations were observed in the hamsters' distal small bowel, whereas that of the guinea pig was unaffected. Sodium deoxycholate $(2 \mathrm{mM})$ resulted in significant injury to the proximal and distal small intestine of both species. The degree of injury was more pronounced in the proximal segment of the hamster but was similar in both segments of the guinea pig. Sodium chenodeoxycholate ( 1 and $2 \mathrm{mM}$ ) produced alterations in the proximal small intestine of both species which generally appeared greater than the distal changes.

When absorption of a perfused bile salt was measured by recovery from a bile fistula (Table IV), perfusion with $5 \mathrm{mM}$ sodium cholate for one hour led to absorption of $1.2 \mu \mathrm{M}$ from proximal segments and $35 \mu \mathrm{M}$ from distal segments. When $2 \mathrm{mM}$ sodium chenodeoxycholate was perfused, absorption from proximal segments was $18 \mu \mathrm{M}$ and from distal segments $28 \mu \mathrm{M}$.

\section{Discussion}

In these experiments we have attempted to develop a preparation for evaluating the acute effect of individual bile salts on intestinal mucosal morphology. We have compared the results of incubations in vitro with an in-vivo perfusion system. During perfusion in vivo we have also measured bile salt absorption in order to try to assess whether penetration through the mucosa 
may be a factor in causing histological changes. Unconjugated bile salts were used because of the relative ease with which they pass through the intestinal wall by means other than active transport; however, they occur in the upper small intestine to a significant extent only in cases where an abnormal bacterial flora exists.

Incubation in vitro tended to obscure more subtle changes, since small intestinal tissue incubated in Krebs-Ringer solution in the absence of bile salts invariably showed separation of epithelium from the lamina propria and often mild shedding of cells from villous tips. Inclusion of physiological amounts of divalent cations into the incubating media neither enhanced nor lessened these effects. Our data extend the morphological findings in vitro of Dawson and Isselbacher (1960) in the rat. These authors showed 'dissolution of the tissue with loss of whole villi' at the end of a one-hour incubation of intestinal rings from the upper two-thirds of the small intestine in the presence of $1-5 \mathrm{mM}$ deoxycholate, a finding confirmed by Donaldson (1965) at $0.6 \mathrm{mM}$ concentration. Dawson and Isselbacher further showed that cholate at $15 \mathrm{mM}$ concentration produced 'histological damage to all villi' when compared with incubations in KrebsRinger solution containing $1 \mathrm{mM}$ glucose, which produced only 'scattered mild mucosal damage'. An appearance identical to the control was found with glycocholate and taurocholate at $20 \mathrm{mM}$ (Dawson and Isselbacher, 1960). Our studies in vitro further show that histological changes greater than those in control experiments are produced by sodium chenodeoxycholate and deoxycholate at $2.5 \mathrm{mM}$ and $5 \mathrm{mM}$ and that these changes are similar in degree in gut segments taken from proximal and distal bowel. Only with $5 \mathrm{mM}$ cholate incubation of guinea pig intestine was significantly less damage found proximally than distally. This is interesting in view of the negligible absorption in vivo of $5 \mathrm{mM}$ cholate from guinea pig proximal small intestine compared with $2 \mathrm{mM}$ chenodeoxycholate which is better absorbed proximally. This suggests the possibility that histological changes in this region may be related in part to the degree to which bile salts are able to traverse the bowel wall.

Regional differences were readily demonstrable with perfusion in vivo of bile salts, and the degree of damage with similar bile salt concentration tended to be less severe than that observed after incubation in vitro. This may be attributed to the presence of an intact vascular system with perfusion in vivo, and possibly to lessened trauma when tissues are not everted and shaken mechanically.

The perfusion studies in vivo indicate that dihydroxy bile salts produce more marked alterations of proximal small intestine than does the trihydroxy bile salt, sodium cholate. Cholate concentrations of $5 \mathrm{mM}$ failed to produce mucosal alterations proximally, the changes again being confined to the distal small intestine. When absorption of sodium cholate was measured in these experiments, the amount of bile salt absorbed from the distal small intestine was approximately thirty times that absorbed from the proximal small intestine during the one hour perfusion. In contrast, mild to severe changes in morphology of both proximal and distal small intestine were readily apparent with the dihydroxy bile salts, deoxycholate and chenodeoxycholate, at only $2 \mathrm{mM}$ concentrations in both animals, and also at $1 \mathrm{mM}$ in the hamster. The changes induced by dihydroxy bile salts tended to be more severe in the proximal than in the distal small intestine.

At least two factors must be considered in evaluating these observations. First, the penetration of bile salts into the cell, and second, the chemical toxicity of the bile salt. In the proximal small intestine intracellular penetration occurs only by passive processes (Weiner and Lack, 1962). The more polar trihydroxy bile salt would be expected to have a lesser degree of penetrance than the dihydroxy bile salts. We have shown that $2 \mathrm{mM}$ sodium chenodeoxycholate is absorbed from the proximal small intestine of the guinea pig fifteen times more rapidly than $5 \mathrm{mM}$ sodium cholate. The lesser proximal absorption of cholate may explain in part its lack of effect on the proximal small bowel in the experiments in vivo.

In the ileum absorption occurs not only by diffusion, but also by the specialized ileal transport system which acts on both conjugated and unconjugated bile salts (Lack and Weiner, 1961; Weiner and Lack, 1962). Here, similar degrees of morphological damage were evident with sodium cholate at $5 \mathrm{mM}$ and with sodium chenodeoxycholate and deoxycholate at $2 \mathrm{mM}$ concentration, suggesting a greater chemical toxicity of the dihydroxy bile salts. In contrast, conjugated bile salts have been shown to result in minimal morphological changes and to have little toxicity as judged by action on metabolism and transport of water-soluble nutrients by rat jejunum in vitro (Pope et al, 1966; Dietschy, 1967; Holt, 1966).

The fact that unconjugated dihydroxy bile salts lead to significantly greater alterations in morphology in proximal than in distal small intestine can hardly be explained by greater mucosal penetration proximally, since the potential for cellular entry is greater distally where two absorptive processes operate. Indeed, our measurements show greater absorption distally, even when corrections are made for the slight differences in length of intestine perfused. Furthermore, radioautographic studies (Schneider, 1967, unpublished data) of gut samples taken during such perfusion suggest that concentrations of bile salts in ileal segments are at least five times those in more proximal segments of small intestine. Rather, it would seem 
reasonable to speculate on a possible adaptation of ileal epithelial cells, which, during normal enterohepatic circulation, are exposed continually to relatively large quantities of bile salts. This adaptation may be species specific. In the guinea pig, deoxycholate is present in very low concentrations, if at all, whereas it is a normal constituent of hamster bile. An increase in sodium deoxycholate concentration from $1 \mathrm{mM}$ to $2 \mathrm{mM}$ led to a much greater increase in damage to the guinea pig ileum than to the hamster ileum. The observation that $2 \mathrm{mM}$ sodium chenodeoxycholate produces considerably less change in the ileum than in the proximal small intestine of the guinea pig is in accord with this hypothesis, since chenodeoxycholate is the principal bile salt native to the guinea pig. The bile salts used in this study are all native to the hamster. In keeping with the above thesis of species specific resistance, morphological alterations with all these bile salts, at all concentrations tested except $2 \mathrm{mM}$ chenodeoxycholate, were more apparent in the proximal than in the distal small intestine of the hamster. It is possible that resistance to the action of unconjugated bile salts may also be acquired. Fry and Staffeldt (1964) showed that in mice fed $2 \%$ deoxycholate, the upper intestine showed changes within two days of institution of the diet. Their illustration closely resembles the $1+$ abnormality shown in our report. At eight days the damage extended down the whole intestine. Thirty-nine days after starting the diet, however, the appearance of the villi was almost normal except for evidence of increased proliferation in the crypts (Fry and Staffeldt, 1964).

The markedly greater absorption of sodium chenodeoxycholate than sodium cholate from the proximal small intestine at $p \mathrm{H} 6.8$ has not been demonstrated previously by direct measurement of bile salt in the bile. Recent preliminary data of Hislop, Hoffman, and Schoenfield (1966), using a triple-lumen tube to perfuse isotopic bile acids and sample them in the human jejunum, are in broad agreement with this finding. Observations in the guinea pig (Weiner and Lack, 1962) have shown negligible absorption of sodium cholate buffered to $p \mathrm{H} \mathrm{7.0} \mathrm{when} \mathrm{introduced} \mathrm{into}$ an isolated proximal segment of small intestine in vivo. Tidball (1964) found $43 \%$ recovery of cholic acid in three hours from rat jejunum, and mentions that studies in the guinea pig were similar. The $p \mathrm{H}$ of the bile salt introduced into the segment is not stated. Relatively slight changes in the $p \mathrm{H}$ of the mucosal solution in the range of $p \mathrm{H} \mathrm{6.0-8.0} \mathrm{result} \mathrm{in} \mathrm{marked} \mathrm{changes} \mathrm{in}$ the relative amounts of cholate ion and unionised cholic acid and, therefore, in the degree of passive non-ionic diffusion (Dietschy et al, 1966).

There are no published data other than those reported here on the absorption of chenodeoxycholate from the proximal small bowel of experimental animals. It would seem likely that the greater proximal absorption of sodium cheno- deoxycholate at a comparable $p H$ in these experiments may be related to a greater fat solubility of the undissociated molecule.

We are particularly grateful to Dr M. P. Tyor and to Dr Leon Lack for continuous advice and assistance. This work was supported by Research grants AM 11730 and AM 12107 from the United States Public Health Service, and that of Dr Schneider by training grant AM 5093 from the United States Public Health Service.

Please address requests for reprints to William O. Dobbins, III, MD, Veterans Administration Hospital, 50 Irving Street, N.W., Washington, DC 20422.

\section{References}

Dawson, A. M., and Isselbacher, K. J. (1960). Studies on lipid metabolism in the small intestine with observations on the role of bile salts. J. clin. Invest., 39, 730-740.

Dietschy, J. M. (1967). Effects of bile salts on intermediary metabolism of the intestinal mucosa. Fed. Proc., 26, 1589-1598.

Dietschy, J. M., Salomon, H. S., and Siperstein, M. D. (1966). O Bile acid metabolism, I. Studies on the mechanism of intestinal transport. J. clin. Invest., 15, 832-846.

Donaldson, R. M., Jr. (1965). Studies on the pathogenesis of steatorrhea in the blind loop syndrome. J. clin. Invest., 44, 1815-1825.

Forth, W., Rummel, W., and Glasner, H. (1966). Zur resorptionshemmenden Wirkung von Gallensäuren. Naunyn-Schmiedberg's Arch. exp. Path. Pharmak., 354, 364-380.

Fry, R. J., and Staffeldt, E. (1964). Effect of a diet containing sodium deoxycholate on the intestinal mucosa of the mouse. Nature (Lond.), 203, 1396-1398.

Haslewood, G. A. D. (1964). The biological significance of chemical differences in bile salts. Biol. Rev., 39, 537-574.

Heaton, K. W., and Lack, L. (1968). Ileal bile salt transport: Mutual inhibition in an in vivo system. Amer. J. Physiol., 214, 585-590.

Hislop, I. G., Hoffman, A. F., and Schoenfield, L. G. (1966). Determinants of the rate and site of bile acid absorption in man. J. clin. Invest., 46 (abstr.), 1070-1071.

Holt, P. R. (1966). Competitive inhibition of intestinal bile salt absorption in the rat. Amer. J. Physiol., 210, 635-639.

Kim, Y. S., Spritz, N., Blum, M., Terz, J., and Sherlock, P. (1966). The role of altered bile acid metabolism in the steatorrhea of experimental blind loops. J. clin. Invest., 45, 956-962.

Lack L., and Weiner, I. M. (1961). In vitro absorption of bile salts by small intestine of rats and guinea pigs. Amer. $J$. Physiol., 200, 313-317.

Low-Beer, T. S., Tyor, M. P., and Lack, L. (1969). The effects of sulfation of taurolithocholic and glycolithocholic acids on their intestinal transport. Gastroenterology, 56, 721-726.

Norman, A. (1956). Preparation of conjugated bile acids using mixed carboxylic acid anhydrides. Bile acids and steroids. Arkiv. Kemi. 8, 331-334.

Norman, A., and Sjovall, J. (1958). On the transformation and enterohepatic circulation of cholic acid in the rat. J. biol. Chem., 233, 872-885.

Palade, G. E., and Siekevitz, P. (1956). Liver microsomes: An integrated morphological and biochemical study. J. Biophys. Biochem. Cytol. 2, 171-200.

Pope, J. L., Parkinson, T. M., and Olson, S. A. (1966). Action of bile salts on the metabolism and transport of water-soluble nutrients by perfused rat jejun um in vitro. Biochim. biophys Acta (Amst.), 130, 218-232.

Prange, I., Christensen, F., and Dam, H. (1962). Alimentary production of gallstones in hamsters. II. Relation between diet and composition of the bladder bile. Z. Ernährungsw., $3,59-78$.

Rosenberg, I. H., Hardison, W. G., and Bull, D. M. (1967). Abnormal bile salt patterns and intestinal bacterial overgrowth associated with malabsorption. New Eng. J. Med., 276, 1391-1397.

Tabaqchali, S., and Booth, C. C. (1966). Jejunal bacteriology and bile salt metabolism in patients with intestinal malabsorption. Lancet, 2, 12-15.

Tidball, C. S. (1964). Intestinal and hepatic transport of cholate and organic dyes. Amer. J. Physiol., 206, 239-242.

Weiner, I. M., and Lack, L. (1962). Absorption of bile salts from the small intestine in vivo. Amer. J. Physiol., 202, 155-157.

Weissman, G. (1964). Lysosomes. Blood, 24, 594-606.

Whitehouse, M. W., and E. Staple (1959). Regulation of cholesterol oxidation by the liver in vitro. Proc. Soc. exper. Biol., 101, 439-441. 